\title{
Workshop on Drug Effects in Animals
}

Classification of Psychotropic Drugs by Means of Animal EEG and Sleep Studies
Boca Raton, Fla., USA
May 24, 1992
Editors
F.N. CM. Krijzer, Weesp

W.M. Herrmann, Berlin

I7figuresand 14 tables 1993

\section{KARGEH}


The authors and the publisher have exerted every effort to ensure that drug selection and dosage set forth in this text are in accord with current recommendations and practice at the time of publication. However, in view of ongoing research, changes in government regulations, and the constant now of information relating to drug therapy and drug reactions, the reader is urged to check the package insert for each drug for any change in indications and dosage and for added warnings and precautions. This is particularly important when the recommended agent is a new and/or infrequently employed drug. 


\section{Contents}

\section{Preface}

van Riezen, H.; Glatt, A.F.

Introduction and History of the Use of Electroencephalography in Animal Drug Studies

Krijzer, F.; Koopman, P.; Olivier, B.

Classification of Psychotropic Drugs Based on Pharmacoelectrocorticographic Studies in Vigilance-Controlled Rats

Ruigt, G.S.F.; Engelen, S.; Gerrits, A.; Verbon, F.

Computer-Based Prediction of Psychotropic Drug Classes Based on a Discriminant Analysis of Drug Effects on Rat Sleep

Lancel, M.

Cortical and Subcortical EEG in Relation to Sleep-Wake Behavior in Mammalian Species

Sarkadi, A.; Ambrus, A.; Szporny, L.

Responses in Rats

160

Classification of Drugs Based on Visually Evoked 